\title{
Hearing loss among elderly people and access to hearing aids: a cross-sectional study from a rural area in Germany
}

\author{
Birgit Didczuneit-Sandhop ${ }^{1}$ (1) $\cdot$ Katarzyna Jóźwiak $^{2} \cdot$ Manja Jolie $^{1} \cdot$ Josefine Holdys $^{1} \cdot$ Michael Hauptmann $^{2,3}$ (C)
}

Received: 1 October 2020 / Accepted: 1 April 2021 / Published online: 18 April 2021

(c) The Author(s) 2021

\begin{abstract}
Purpose Hearing loss is common and associated with reduced quality of life, particularly among elderly people. However, many patients do not use hearing aids. We evaluated the use of hearing aids among people with hearing loss by health services availability near their residence in a rural area in the state of Brandenburg, Germany.

Methods Audiometry was performed in a convenience sample of subjects in ten towns and hearing loss was determined, defined as a threshold of $\geq 30 \mathrm{~dB}$ in at least one ear and at least one of the frequencies 0.5, 1.0, $2.0 \mathrm{and} 4.0 \mathrm{kHz}$. For each participant, age and gender were collected and whether or not hearing aids were available.

Results Among 186 persons with an average age of 74 years (interquartile range 71-81), 97\% had hearing loss [95\% confidence interval (CI) 95-100]. Among 121 patients with hearing loss who reported whether or not they have a hearing aid, 93 had no hearing aid (77\%, 95\% CI 69-84). The proportion of hearing-impaired persons who do not have a hearing aid significantly increased with the absence of a hearing aid specialist or ear nose throat (ENT) physician or both in the town where the tests were performed ( $p$ trend $=0.001$ ).

Conclusion Hearing loss is common among elderly people in the study area and many people in rural areas in Germany may not be properly supplied with hearing aids due to lack of hearing aid specialists and/or ENT physicians close to their residence. Interventions to improve this situation are urgently required.
\end{abstract}

Keywords Hearing loss $\cdot$ Rural $\cdot$ Audiometry $\cdot$ Hearing aid $\cdot$ Health services

\section{Introduction}

Over $5 \%$ of the world's population suffer from hearing impairment defined as hearing loss greater than $40 \mathrm{~dB}$ in the better hearing ear for adults and greater than $30 \mathrm{~dB}$ for children. It is estimated that by 2050 over 900 million people—or one in ten-will have disabling hearing loss [1]. The most common cause of hearing impairment in elderly people is age-related hearing loss or presbyacusis. Other causes for

Birgit Didczuneit-Sandhop

disa@klinikum-brandenburg.de

1 Department of Otorhinolaryngology, Head and Neck Surgery, University Hospital Brandenburg, Brandenburg Medical School Theodor Fontane, Brandenburg a.d. Havel, Germany

2 Institute of Biostatistics and Registry Research, Brandenburg Medical School Theodor Fontane, Neuruppin, Germany

3 Faculty of Health Sciences Brandenburg, Brandenburg Medical School Theodor Fontane, Neuruppin, Germany hearing loss in adulthood are chronic otitis media and acoustic trauma [2].

Hearing loss can have profound effects on health, since it is associated with poor cognitive performance [3], increased risk of falls [4], acceleration of dementia [5], social isolation and psychiatric disorders including depression, anxiety and schizophrenia [6-8]. Therefore, hearing loss is now the fourth (men) and seventh (women) leading cause of years lived with disability in the Global Burden of Disease Study [9], higher than many other diseases such as stroke, falls and dementia.

Presbyacusis is underdiagnosed and undertreated in Germany. A recent systematic review on hearing loss in Germany [10] identified only six available cross-sectional studies [11-16]. The observed proportion ranged between 16 and $25 \%$ and varied by age, study design and definition of hearing loss. Two studies indicate that the majority of patients are not properly supplied with hearing aids $[12,15]$. An urgent need for advanced studies of the 
determinants of and interventions against untreated hearing impairment was expressed [17].

Definitions of hearing loss are very heterogeneous and use different thresholds $(\mathrm{dB})$ for at least one or the average of several frequencies (commonly $0.5,1,2$ and $4 \mathrm{kHz}$ ) in at least one ear or in the better hearing ear [10]. According to the World Health Organization, disabling hearing loss is defined as an average threshold exceeding $40 \mathrm{~dB}$ for the frequencies $0.5,1,2$ and $4 \mathrm{kHz}$ in the better hearing ear. Here, we apply the definition used by German health insurances as an indication for a hearing aid, which is a threshold of $\geq 30 \mathrm{~dB}$ for at least one of the frequencies 0.5 , 1,2 and $4 \mathrm{kHz}$ in at least one ear.

Potential inequalities of health and health care in rural areas are of great concern not only in developing but also in industrialized countries [18], and about $30 \%$ of the area of European countries is considered thinly populated, i.e., $<100$ inhabitants per $\mathrm{km}^{2}$ [19]. Indeed, Koster et al. [20] showed that in Western-European countries (including France, UK, Norway, Netherlands and Germany), several health indicators suggested better health among people living in urban areas compared to the total population. Investigating the rural component of diseases of high global burden, such as hearing loss, is therefore, key to understand and improve the public's health.

We report the results of a small pilot study on the extent and determinants of untreated hearing impairment in a rural area of Germany, to prepare a comprehensive study from which interventions can be conceived.

\section{Methods}

\section{Study population}

Ten towns located around the city of Brandenburg a. d. Havel were visited between May 15 and 21, 2019 by a specifically equipped vehicle for performing audiometry ("Cochlea-Mobil"). A free hearing test was offered to anybody interested, irrespective of any exclusion criteria. The opportunity of free hearing tests was widely advertised beforehand in newspapers and posters in the cities.

\section{Hearing level measurements}

The vehicle was noise-insulated and equipped with a microaudiometer (MA33, Maico). Audiometry was conducted by an ENT physician from the hospital in Brandenburg a. d. Havel. Participants were considered to have hearing loss, if the threshold for at least one of the frequencies $0.5,1.0,2.0$ and $4.0 \mathrm{kHz}$ was $\geq 30 \mathrm{~dB}$ for at least one ear. Only air conduction was measured. The results were communicated to the participant and self-reported information on age, gender and availability of hearing aids was documented.

\section{Statistical analysis}

We evaluated whether the participants with and without hearing loss differed by town, age, and gender using Fisher's exact test (town, gender) and the Mann-Whitney $U$ test (age). We calculated percentages of persons with no hearing devices among the persons with hearing loss. We tested whether the proportion of patients with untreated hearing impairment was associated with the absence of health professionals (hearing aid specialist, ENT physician or both) in the town using a linear-by-linear trend test for ordered proportions (order: no hearing aid specialist and no ENT physician, hearing aid specialist or ENT physician, hearing aid specialist and ENT physician). Null hypotheses were rejected when the two-sided $p$ value was $5 \%$ or less. The statistical software STATA/SE 16 was used (Stata Corp 2019).

\section{Results}

Audiometry was conducted for 186 persons and information on age (average 74.4 years; range 37-93) and gender (55.7\% female) was provided by 148 and 149 persons, respectively. Hearing loss was detected in 181 participants [97\%, 95\% confidence interval (CI) 95-100] (Table 1). The average threshold for the right (left) ear was $47.5 \mathrm{~dB}(48.0 \mathrm{~dB})$ across frequencies $0.5,1.0,2.0$ and $4.0 \mathrm{kHz}$.

The proportion of patients with hearing loss was similar across towns ( $p=0.307)$ : $94 \%$ in Bad Belzig, $97 \%$ in Lehnin/Brück and Treuenbrietzen, 94\% in Luckenwalde/ Jüterbog, 100\% in Premnitz and Genthin, 97\% in Rathenow and $100 \%$ in Ziesar (Table 1).

For 121 patients with hearing loss, it is known whether they have a hearing aid. Of those, 93 had no hearing aid (77\%, 95\% CI 69-84). The proportion of patients with hearing loss who do not have a hearing aid is increasing from 45 patients $(67 \%)$ in towns with an ENT physician and a hearing aid technician (Bad Belzig, Premnitz/Genthin) to $24(80 \%)$ in towns with only a hearing aid technician (Rathenow) to 24 patients (100\%) in towns with neither profession (Ziesar and Lehnin/Brück/Treuenbrietzen), which is a significant trend $(p=0.001)$ (Table 2).

Data per ear by hearing thresholds above 60,70 and $80 \mathrm{~dB}$ at $0.5,1.0,2.0$, and $4.0 \mathrm{kHz}$ were available for 181 patients and 354 ears (for 8 patients, values were known for only 1 ear). An average hearing loss exceeding $60(70,80)$ $\mathrm{dB}$ was observed in $87(48,22)$ ears $(24.6 \%, 13.6 \%, 6.2 \%)$, including $26(13,9)$ ears without a hearing aid. 
Table 1 Overview of study population

\begin{tabular}{|c|c|c|c|c|}
\hline & \multicolumn{2}{|l|}{ Hearing loss ${ }^{\mathrm{a}}$} & \multirow{2}{*}{$\begin{array}{l}\text { Total } \\
N\end{array}$} & \multirow[t]{2}{*}{$p$ value $^{\mathrm{b}}$} \\
\hline & $\begin{array}{l}\text { Yes } \\
N(\%)\end{array}$ & $\begin{array}{l}\text { No } \\
N(\%)\end{array}$ & & \\
\hline \multicolumn{5}{|l|}{ Place of hearing measurement } \\
\hline Bad Belzig & $15(94)$ & $1(6)$ & 16 & \multirow[t]{6}{*}{0.307} \\
\hline Lehnin/Brück/Treuenbrietzen & $28(97)$ & $1(3)$ & 29 & \\
\hline Luckenwalde/Jüterborg & $33(94)$ & $2(6)$ & 35 & \\
\hline Premnitz/Genthin & $52(100)$ & $0(0)$ & 52 & \\
\hline Rathenow & $30(97)$ & $1(3)$ & 31 & \\
\hline Ziesar & $23(100)$ & $0(0)$ & 23 & \\
\hline \multicolumn{5}{|l|}{ Gender } \\
\hline Female & $81(98)$ & $2(2)$ & 83 & \multirow[t]{3}{*}{0.999} \\
\hline Male & $64(97)$ & $2(3)$ & 66 & \\
\hline Unknown & $36(97)$ & $1(3)$ & 37 & \\
\hline \multicolumn{5}{|l|}{ Age at hearing measurement } \\
\hline Mean (IQR), yrs & $75.1(71,81)$ & $50.5(40.5,60.5)$ & $74.4(70.5,81)$ & \multirow[t]{2}{*}{0.003} \\
\hline Unknown & $37(97)$ & $1(3)$ & 38 & \\
\hline \multicolumn{5}{|l|}{ Hearing device } \\
\hline Yes & $28(100)$ & $0(0)$ & 28 & \multirow[t]{3}{*}{0.999} \\
\hline No & $93(98)$ & $2(2)$ & 95 & \\
\hline Unknown & $60(95)$ & $3(5)$ & 63 & \\
\hline Total & $181(97)$ & $5(3)$ & 186 & \\
\hline
\end{tabular}

${ }^{\mathrm{a}}$ Hearing loss was defined as an average threshold of $30 \mathrm{~dB}$ or more for at least one of the frequencies 0.5 , $1.0,2.0$ and $4 \mathrm{kHz}$ in at least one ear

${ }^{\mathrm{b}}$ Fisher's exact test for place, gender and hearing device, Mann-Whitney $U$ test for age among subjects with known values

\begin{tabular}{|c|c|c|c|c|}
\hline \multirow[t]{2}{*}{ Available at place of residence } & \multicolumn{2}{|c|}{ Hearing aid } & \multirow{2}{*}{$\begin{array}{l}\text { Total } \\
N(\%)\end{array}$} & \multirow[t]{2}{*}{ Trend $P^{a}$} \\
\hline & $\begin{array}{l}\text { No } \\
N(\%)\end{array}$ & $\begin{array}{l}\text { Yes } \\
N(\%)\end{array}$ & & \\
\hline Hearing aid technician and ENT physician ${ }^{b}$ & $45(67)$ & $22(33)$ & 67 & 0.001 \\
\hline Hearing aid technician, no ENT physician ${ }^{c}$ & $24(80)$ & $6(20)$ & 30 & \\
\hline No hearing aid technician and no ENT physician ${ }^{\mathrm{d}}$ & $24(100)$ & $0(0)$ & 24 & \\
\hline Total & $93(77)$ & $28(23)$ & 121 & \\
\hline
\end{tabular}

${ }^{a}$ Linear-by-linear test of the null hypothesis of no increase or decrease of the proportion of patients with hearing aids by availability of hearing aid technician and/or ENT physician at the place of residence

${ }^{\mathrm{b}}$ Towns were Bad Belzig, Premnitz/Genthin

${ }^{\mathrm{c}}$ Town was Rathenow

${ }^{\mathrm{d}}$ Towns were Ziesar, Lehnin/Brück/Treuenbrietzen

\section{Discussion}

In a cross-sectional convenience sample of mostly elderly people from ten rural towns in the German state of Brandenburg, we observed a high proportion of patients with hearing loss. The majority of patients with hearing loss did not have hearing aids. The proportion of underserved patients decreases with the availability of health professionals in the towns.
The proportion of patients with hearing loss was $97 \%$, where hearing loss was defined as a threshold of $30 \mathrm{~dB}$ or more in at least one ear and at least one of the frequencies $0.5,1.0,2.0$ and $4.0 \mathrm{kHz}$, which is one indicator for qualifying for a hearing aid. In the HörMat study [11], a hearing loss of $77.8 \%$ in patients older than 60 years with hearing impairment defined as $\geq 25 \mathrm{~dB}$ in one of the frequencies between 0.5 and $4.0 \mathrm{kHz}$ was observed. Lower proportions ranging between 16 and $25 \%$, depending on age and 
definition of hearing loss, were observed in a recent review [10]. Sohn and Jörgenshaus [15], who included patients aged above 14 years in a primary care practice, diagnosed hearing loss in $19 \%$ of their patients with thresholds of $\geq 40 \mathrm{~dB}$ for one of the frequencies $0.5,1.0,2.0$ or $4.0 \mathrm{kHz}$. In the HörSTAT study [12], patients between 18 and 97 years of age were included (Table 3).

The preceding summary illustrates the heterogeneity of definitions for hearing loss used in different studies, which complicates the interpretation of corresponding proportions. We chose our definition, because it is used by German health insurances for the indication of a hearing aid. The study with the most similar definition of hearing loss [11], i.e., $\geq 25 \mathrm{~dB}$ instead of $\geq 30 \mathrm{~dB}$, also observed a high proportion of patients with of hearing loss (77.8\%), albeit lower than the $97 \%$ observed in our study. An explanation could be older age and possible self-selection in our study. If we apply the $25 \mathrm{~dB}$ threshold used in the HörMat study [11] to our data, the proportion of patients with hearing loss is 98\% (95\% CI 97-100\%). The proportion of disabling hearing loss according to the World Health Organization, i.e., more than an average of $40 \mathrm{~dB}$ for frequencies $0.5,1,2$ and $4 \mathrm{kHz}$, is $59 \%$ (95\% CI 52-66\%) in our data (https://www. who.int/pbd/deafness/estimates/en/, accessed Dec 17, 2020). Studies with substantially lower proportions of hearing loss either based their definition on the average over four frequencies rather than at least one frequency [12], used subjective criteria $[13,14]$, or used substantially higher thresholds (e.g., $\geq 40 \mathrm{~dB}$ [15]). Therefore, the observed proportion of patients with hearing loss in our study is indeed very high compared to other studies but is not per se inconsistent.

The observed proportion of subjects without hearing aids among all subjects with hearing loss greater or equal than $30 \mathrm{~dB}(77 \%)$ was higher compared with two studies identified in the review by Löhler et al. [10]. Von Gablenz et al. [21] reported 5.8\% (age 60-69 years), 18.3\% (70-79 years) and $32.6 \%$ ( $\geq 80$ years) in the HörSTAT study, while Sohn and Jörgenshaus [15] observed that $2 \%$ of all participants had a hearing aid while the proportion of patients with of hearing impairment was $16 \%$.

Our data show that untreated hearing loss is common in rural areas and may reach close to $100 \%$ in areas with no hearing aid technician and no ENT physician. This is consistent with Chan et al. [22], who observed that distance to hearing healthcare services was associated with the timing of acquisition of hearing aids. Key motivators to seek care include degree of hearing loss, self-efficacy, family support, and self-recognition of hearing loss [23].

The need for optimal rehabilitation of hearing impairments is not only important for optimal sound transmission to the auditory cortex. In addition, it is known that the auditory impulse on vestibulospinal reactions is an important component in balance regulation [24]. Dawes et al. [25] observed an association between hearing aid use and better cognition. Also, hearing aid use is associated with delayed diagnosis of dementia, depression and anxiety [26].

Our preliminary study includes only a small number of self-selected participants. It is possible that the observed proportion of hearing loss is an overestimate, since hearingimpaired persons may have been particularly attracted by the offer of a cost-free audiometry test. Moreover, only limited demographic and other patient-specific information was recorded, and was entirely missing for a fraction of the subjects. However, our study has several strengths. Audiometry was performed by ENT physicians on standardized equipment in a vehicle which was specifically noise-insulated for this purpose. The high proportion of hearing-impaired persons allowed us to estimate the percentage of underserved patients with high precision $(77 \%, 95 \%$ CI $69-84)$. The knowledge about the availability of hearing aid technicians and/or ENT physicians in the selected areas enabled us to evaluate determinants of underserving in Germany.

Although our study took place in a local context, the relevance of the objective goes far beyond the particular region

Table 3 Overview of definitions of hearing loss and observed proportions in a selection of previous studies in Germany

\begin{tabular}{|c|c|c|c|}
\hline References & Age (years) & Definition of hearing loss & Proportion $(\%)$ \\
\hline Löhler et al. [11] & $60-75$ & $\begin{array}{l}\text { Average threshold of } \geq 25 \mathrm{~dB} \text { for at least one of the frequencies } 0.5,1,2 \\
\text { or } 4 \mathrm{kHz}\end{array}$ & 77.8 \\
\hline Von Gablenz et al. [12] & $18-97$ & Average threshold of $>25 \mathrm{~dB}$ for the frequencies $0.5,1,2$ and $4 \mathrm{kHz}$ & 15.7 \\
\hline Robert Koch Institut [13] & $>18$ & Subjective self-assessment & $\begin{array}{l}\text { Minor difficulties: } 18.8 \\
\text { major difficulties: } 2.7\end{array}$ \\
\hline Neubauer and Gmeiner [14] & $19-\geq 90$ & According to ICD-10 & $\begin{array}{l}\sim 10 \% \text { over age } 70 ; \text { up } \\
\text { to } 15 \% \text { over } 80 \text { years } \\
\text { of age }\end{array}$ \\
\hline Sohn and Jörgenshaus [15] & $>14$ & $\begin{array}{l}\text { Average threshold of } \geq 40 \mathrm{~dB} \text { for at least one of the frequencies } 0.5,1,2 \text {, } \\
3 \text { or } 4 \mathrm{kHz}\end{array}$ & 19 \\
\hline This study & $37-93$ & $\begin{array}{l}\text { Average threshold of } \geq 30 \mathrm{~dB} \text { for at least one of the frequencies } 0.5,1,2 \\
\text { and } 4 \mathrm{kHz} \text { in at least one ear }\end{array}$ & 97 \\
\hline
\end{tabular}


studied. Thinly populated areas are common in all European countries (on average $30 \%$ of the area), and population density is known to be inversely correlated with health in industrialized countries [20]. The patterns observed here may, therefore, generalize to substantial proportions of the population in countries such as Germany, France, the Netherlands, Spain, and the UK.

Hearing loss can have profound effects not only on interpersonal communication, but also on health, independence, wellbeing, quality of life, and daily function. It is a field in which modest interventions have the potential of producing a substantial reduction in the global burden of disease. Large representative studies are needed, particularly in rural areas, to assess the level of hearing loss, the fraction of persons without adequate help and the reasons for this, so that interventions, such as mobile diagnostic units, can be designed and evaluated. These interventions aim to improve the hearing of the population to increase their quality of life and to prevent severe morbidity known to be associated with untreated hearing loss, such as falls, dementia, depression, and other diseases.

Author contributions BDS is the principal investigator. BDS, MJ and $\mathrm{JH}$ contributed to the design of the study. BDS, MJ and JH collected the data. KJ and $\mathrm{MH}$ analyzed the data. All authors read, commented on and approved the manuscript.

Funding Open Access funding enabled and organized by Projekt DEAL. The company "Cochlea" provided the equipped car for free. Staff operating the audiometry equipment was employed by the institutions of the authors. The company was not involved in the collection or analysis of the data or in drafting the manuscript.

Availability of data and materials The data are available upon reasonable request to the corresponding author.

Code availability The STATA code for the analysis of the data is available upon reasonable request to the corresponding author.

\section{Declarations}

Conflict of interest The authors report no conflicts of interest.

Ethics approval Approval of this study by the Institutional Review Board of the Brandenburg Medical School was waived, because only anonymized data were collected.

Consent to participate All participating subjects provided written informed consent.

Consent for publication All authors have approved of the submitted version of this manuscript.

Open Access This article is licensed under a Creative Commons Attribution 4.0 International License, which permits use, sharing, adaptation, distribution and reproduction in any medium or format, as long as you give appropriate credit to the original author(s) and the source, provide a link to the Creative Commons licence, and indicate if changes were made. The images or other third party material in this article are included in the article's Creative Commons licence, unless indicated otherwise in a credit line to the material. If material is not included in the article's Creative Commons licence and your intended use is not permitted by statutory regulation or exceeds the permitted use, you will need to obtain permission directly from the copyright holder. To view a copy of this licence, visit http://creativecommons.org/licenses/by/4.0/.

\section{References}

1. WHO Fact sheet on deafness and hearing loss (2020) https://www. who.int/news-room/fact-sheets/detail/deafness-and-hearing-loss

2. Zahnert T (2011) The differential diagnosis of hearing loss. Dtsch Arztebl Int 108(25):433-444

3. Golub JS, Brickman AM, Ciarleglio AJ, Schupf N, Luchsinger JA (2019) Association of subclinical hearing loss with cognitive performance. JAMA Otolaryngol Head Neck Surg 146(1):57-67

4. Lubetzky AV (2020) Balance, falls, and hearing loss: is it time for a paradigm shift? JAMA Otolaryngol Head Neck Surg 146(6):535-536

5. Leverton T (2015) Hearing loss is important in dementia. BMJ 350:h3650

6. Blazer DG (2018) Hearing loss: the silent risk for psychiatric disorders in late life. Psychiatric Clinics 41(1):19-27

7. Panza F, Quaranta N, Logroscino G (2018) Sensory changes and the hearing loss-cognition link: the cognitive ear. JAMA Otolaryngol Head Neck Surg 144(2):127-128

8. Rutherford BR, Brewster K, Golub JS, Kim AH, Roose SP (2018) Sensation and psychiatry: linking age-related hearing loss to late-life depression and cognitive decline. Am J Psychiatry 175(3):215-224

9. Global Burden of Disease (2018) Global, regional, and national incidence, prevalence, and years lived with disability for 354 diseases and injuries for 195 countries and territories, 1990-2017: a systematic analysis for the Global Burden of Disease study 2017. Lancet 392(10159):1789-1858

10. Löhler J, Walther LE, Hansen F, Kapp P, Meerpohl J, Wollenberg B, Schönweiler R, Schmucker C (2019) The prevalence of hearing loss and use of hearing aids among adults in Germany: a systematic review. Eur Arch Otorhinolaryngol 276(4):945-956

11. Löhler JL, Segler M, Volkenstein V, Battmer S, Ernst RD, Gräbner A, Schlattmann F, Schönweiler P, Wollenberg R, Dazert B (2018) Der Mini-Audio-Test (MAT) — eine Screeningmethode auf Schwerhörigkeit für Haus- und Fachärzte. Laryngorhinootologie 98:27-34

12. von Gablenz P, Hoffmann E, Holube I (2017) Prevalence of hearing loss in Northern and Southern Germany. German version HNO 65(8):663-670

13. Robert-Koch-Institut (2012) Daten und Fakten. Ergebnisse der Studie "Gesundheit in Deutschland aktuell 2010". Beiträge zur Gesundheitsberichterstattung des Bundes. RKI, Berlin, pp 79-82

14. Neubauer G, Gmeiner A (2011) Volkswirtschaftliche Bedeutung von Hörschäden und Möglichkeiten zur Reduktion deren Folgekosten. IfG-Institut für Gesundheitsökonomik, München

15. Sohn W, Jörgenshaus W (2001) Schwerhörigkeit in Deutschland. Z Allg Med 77:143-147

16. Stange G (1992) Hörtest: Wie gut hören die Bürger der (alten) BRD und West-Berlins? TW KopfHals 2:17-21

17. Löhler J, Cebulla M, Shehata-Dieler W, Volkenstein S, Völter C, Walther LE (2019) Hearing impairment in old age: detection, treatment, and associated risks. Dtsch Arztebl Int 116(17):301

18. Scheil-Adlung X (ed) (2015) Global evidence on inequities in rural health protection: new data on rural deficits in health 
coverage for 174 countries. International Labour Office, Social Protection Department, ILO, Geneva

19. WHO Regional Office for Europe (2010) Rural poverty and health systems in the WHO European Region. Copenhagen.

20. Koster EM, de Gelder R, Di Nardo F et al (2017) Health status in Europe: comparison of 24 urban areas to the corresponding 10 countries (EURO-URHIS 2). Eur J Public Health 27(suppl_2):62-67

21. von Gablenz P, Holube I (2015) Prevalence of hearing impairment in northwestern Germany. Results of an epidemiological study on hearing status (HORSTAT). HNO 63(3):195-214

22. Chan S, Hixon B, Adkins M, Shinn JB, Bush ML (2017) Rurality and determinants of hearing healthcare in adult hearing aid recipients. Laryngoscope 127(10):2362-2367

23. Barnett M, Hixon B, Okwiri N, Irungu C, Ayugi J, Thompson R, Shinn JB, Bush ML (2017) Factors involved in access and utilization of adult hearing healthcare: a systematic review. Laryngoscope 127(5):1187-1194
24. Seiwerth I, Jonen J, Rahne T, Schwesig R, Lauenroth A, Hullar TE, Plontke SK (2018) Einfluss des Hörens auf die vestibulospinale Kontrolle. HNO 66(8):590-597

25. Dawes P, Emsley R, Cruickshanks KJ, Moore DR, Fortnum H, Edmondson-Jones M, McCormack A, Munro KJ (2015) Hearing loss and cognition: the role of hearing aids, social isolation and depression. PLoS ONE 10(3):e0119616

26. Mahmoudi E, Basu T, Langa K, McKee MM, Zazove P, Alexander N, Kamdar N (2019) Can hearing aids delay time to diagnosis of dementia, depression, or falls in older adults? J Am Geriatr Soc 67(11):2362-2369

Publisher's Note Springer Nature remains neutral with regard to jurisdictional claims in published maps and institutional affiliations. 